\title{
STUDI PENGGUNAAN TERBAIK DAN TERTINGGI PADA PERUNTUKAN KOMERSIAL DI JALAN MUCHTAR RAYA SAWANGAN KOTA DEPOK
}

\author{
Fransiskus Xaverius Kennedy ${ }^{1)}$, Priyendiswara Agustina Bela ${ }^{2)}$
}

\author{
1)Program Studi S1 PWK, Fakultas Teknik, Universitas Tarumanagara, xaveriuskennedy@gmail.com \\ 2)Program Studi S1 PWK, Fakultas Teknik, Universitas Tarumanagara, priyendiswaraa@ft.untar.ac.id
}

\begin{abstract}
Abstrak
Suatu lahan di Jalan Muchtar Raya Depok merupakan lahan kosong yang mempunyai peruntukan sebagai lahan komersial. Lahan seluas $17.170 \mathrm{~m} 2$ tersebut terletak pada kawasan selatan Depok tepatnya di Kecamatan Sawangan, Kelurahan Sawangan Baru. Sayangnya lahan tersebut masih berupa lahan kosong, padahal letak lahan yang berada di dekat jalan kolektor sekunder dan mempunyai peluang tinggi untuk dikembangkan lebih lanjut dikarenakan dengan adanya perkembangan tren yang mengarah ke Sawangan. Sehingga diperlukan peruntukan untuk jenis properti yang sesuai untuk memperoleh peruntukan yang tertinggi dan terbaik. Untuk mengetahui peruntukan tertinggi dan terbaik pada lahan komersial di Jalan Muchtar Raya dilakukan analisis Highest and Best Use (HBU) pada lahan tersebut. Analisa HBU adalah penggunaan dari suatu lahan untuk mendapatkan peruntukan yang maksimum sehingga mendapatkan penggunaan terbaik dengan aspekaspek yang dianalisa diantaranya adalah aspek lokasi dan tapak, aspek legal, aspek pasar, aspek finansial. Hasil dari penelitian ini didapatkan bahwa Retail dengan skala community merupakan alternatif tertinggi dan terbaik untuk didirikan pada lahan di Jalan Muchtar Raya Depok ini dengan nilai NPV (Rp41.485.881.445) yang berarti proyek layak dikarenakan lebih besar dari >0 kemudian nilai IRR yakni 15,2 \% dengan tingkat suku bunga $12 \%$ yang berarti jika IRR > suku bunga proyek dapat dilaksanakan, kemudian didapatkan profitability index di angka 1,70 yang artinya pengembalian untuk produk properti ini 1,70 lebih besar dari investment yang dilakukan.
\end{abstract}

Kata kunci: lahan komersial; penggunaan terbaik dan tertinggi; properti komersial

\begin{abstract}
A land on Jalan Muchtar Raya Depok is an empty land which has a designation as a commercial land. The area of $17,170 \mathrm{~m} 2$ is located in the southern part of Depok, precisely in Sawangan District, Sawangan Baru Village. Unfortunately, the land is still in the form of vacant land, whereas the location of the land is near the secondary collector road and has a high opportunity to be developed further due to the development of trends that lead to Sawangan. So that allotment is needed for the appropriate type of property to obtain the highest and best allotment. To find out the highest and best allotment of commercial land on Jalan Muchtar Raya, a Highest and Best Use (HBU) analysis was performed on the land. $H B U$ analysis is the use of a land to get the maximum designation so that it gets the best use with the aspects analyzed including the site and site aspects, legal aspects, market aspects, financial aspects. The results of this study found that retail with a community scale is the highest and best alternative to be established on land in Jalan Muchtar Raya Depok with an NPV value $(R p .41,485,881,445)$ which means the project is feasible because it is greater than $>0$ then an IRR value of $15,2 \%$ with an interest rate of $12 \%$ which means that if the IRR > project interest rate can be implemented, then the profitability index is obtained at 1.70 which means that the return for this property product is 1.70 greater than the investment made.
\end{abstract}

Keywords: commercial land; commercial property; highest and best use 


\section{PENDAHULUAN}

\section{Latar Belakang}

Kota Depok merupakan salah satu kota satelit yang merupakan daerah penunjang bagi kotakota besar di sekitarnya dan merupakan sebuah jembatan untuk menuju ke kota besar, karena kota satelit yang mempunyai fungsi sebagai penunjang kota besar sehingga laju pertumbuhan penduduk dan perekonomianpun kian meningkat dan bertumbuh. Hal tersebut bertolak belakang dengan ketersediaan lahan yang kian hari kian terbatas. Sehingga lahan kosong yang ada diharapkan dapat dimanfaatkan dengan seoptimal mungkin.

Sebuah lahan mempunyai sifat yang tetap, yaitu tidak dapat dipindahkan oleh karena itu setiap lahan memiliki keunikannya masing-masing dilihat dari lokasinya, sehingga dapat disimpulkan bahwa sebidang lahan tidak akan sama dengan sebidang lahan lainnya. Oleh karena itu dibutuhkan analisis pemanfaatan lahan yang sesuai dengan karakteristik dari lahan tersebut sehingga dapat menghasilkan pemanfaatan lahan yang efektif sesuai dengan karakter lahan tersebut diperlukan penggunaan metode yang tepat. Dalam kasus ini menggunakan metode highest and best use yang diantaranya terdapat prinsip penilaian yaitu penggunaan dari suatu tanah secara fisik dan lokasi memungkinkan, secara legal dijijinkan, layak secara pasar dan layak secarafinansial.

Terlebih lahan penelitian yang terletak di Sawangan mempunyai pertumbuhan nilai lahan yang cukup signifikan yang disusul oleh adanya potensi yang cukup besar dengan bermunculannya perkembangan kawasan yang mengarah ke arah kawasan sekitar lahan penelitian, kemudian mempunyai tren pasar properti yang cukup baik dan diisukan akan menjadi masa depan dari Kota Depok.

\section{Rumusan Permasalahan}

Terdapat lahan kosong komersial di Jl Muchtar Raya Sawangan yang belum memiliki rencana pengembangan sesuai dengan peruntukannya, yaitu komersial perdagangan dan jasa.

\section{Tujuan}

Penelitian ini bertujuan untuk mengetahui alternatif penggunaan lahan terbaik dan tertinggi pada lahan di II Muchtar Raya seluas $17.170 \mathrm{~m} 2$ yang mempunyai peruntukan komersial dengan mengidentifikasi potensi dan masalah dari lahan tersebut. Lahan tersebut mempunyai potensi untuk didirikan properti komersial seperti apartemen, hotel dan retail. Untuk mengetahui penggunaan lahan terbaik dan tertinggi perlu dilakukan analisis penggunaan terbaik dan tertinggi yang ditinjau dari aspek fisik, legal, pasar, finansial.

\section{KAJIAN LITERATUR}

\section{Konsep Penggunaan Terbaik dan Tertinggi}

Pada buku How to conduct \& analyze real estate market with feasibility study (Barret,1998) Penggunaan terbaik dan tertinggi dapat diartikan sebagai suatu penggunaan lahan yang paling optimal yang layak dari segi keuangan dan diijinkan secara hukum yang akan menghasilkan nilai lahan tertinggi dari pengembangan lahan tersebut. Dalam melakukan HBU terdapat kriteriakriteria yang harus dipenuhi

a. Memungkinkan secara fisik dalam hal ini yang harus ditinjau untuk lahan kosong adalah faktor lokasi dan tapak seperti aksesibilitas lahan, karakteristik, kedekatan dengan pusatpusat kegiatan, bentuk tanah, luas tanah, ketinggian, kontur tanah serta termasuk dalam potensi rawan bencana.

b. Diizinkan oleh peraturan yang ada dapat diartikan pengembangan suatu bangunan tidak melanggar peraturan penggunaan lahan yang telah ditetapkan oleh pemerintah dan 
bangunan apa yang diperbolehkan apabila penggunaan lahan boleh diubah dan mengikuti building code yang ditentukan.

c. Layak dari segi pasar dilihat dari faktor supply dan demand properti yang ada di sekitar lahan yang akan menentukan apakah nantinya ada penyerapan di pasar atau tidak.

d. Layak secara keuangan dapat diartikan secara keuangan dapat menghasilkan keuntungan yang optimal dilihat dari NPV IRR PI dan PP atau menghasilkan nilai lahan yang tertinggi.

- Net Present Value (NPV)

NPV adalah nilai sekarang dari semua benfit net proyek. Jumlah ini didiskontokan pada tingkat diskonto. Pendekatan ini berfungsi untuk menghitung selisih antara nilai sekarang dengan nilai penerimaan-penerimaan kas bersih yang akan datang. Proyek dikatakan layak bila NPV $>0$ Proyek dikatakan tidak layak bila NPV $<0$

- Internal Rate of Return (IRR)

IRR adalah bunga maksimum yang dapat dibayar untuk sumber daya proyek. IRR ini meninggalkan cukup uang untuk menutupi biaya investasi dan operasional. Bila IRR > tingkat discount rate yang ditentukan, maka proyek dinyatakan layak. Sebaliknya apabila IRR < tingkat discount rate maka proyek dinyatakan tidak layak.

- Profitability Index (PI)

Profitability Index bertujuan untuk menghitung perbandingan antara penerimaanpenerimaan yang akan datang. Syarat kelayakan pendekatan ini adalah apabila PI>1, maka proyek tersebut dikatakan layak.

- Payback Period

$$
P i=\frac{\text { Income }}{\text { Investment Cost }}
$$

Payback period adalah suatu jangka waktu kembalinya investasi dengan menggunakan selisih penerimaan bersih yang diterima setiap tahunnya. Pendekatan ini berfungsi untuk mengukur waktu dalam pengembalian investasi terhadap suatu proyek. Syarat kelayakan dengan menggunakan pendekatan ini adalah apabila jangka waktu yang diperoleh lebih pendek dari yang ditentukannya pengembalian maka proyek tersebut layak.

\section{METODE}

\section{Model dan Konsep Penelitian}

Dalam penelitian ini digunakan konsep penggunaan terbaik dan tertinggi yang dapat menghasilkan jenis properti komersial apa yang layak dibangun sesuai dengan prinsip penggunaan terbaik dan tertinggi.

\section{Waktu dan Objek Penelitian}

Waktu penelitian dilakukan pada 2 tahap yakni pra tugas akhir di rentan waktu Agustus 2019 Desember 2019 dan tugas akhir pada Januari 2020 - Juni 2020. Lahan pada objek penelitian ini berupa sebidang tanah kosong di Jl Muchtar Raya Kota Depok dengan besaran luas 17.170 m2. 


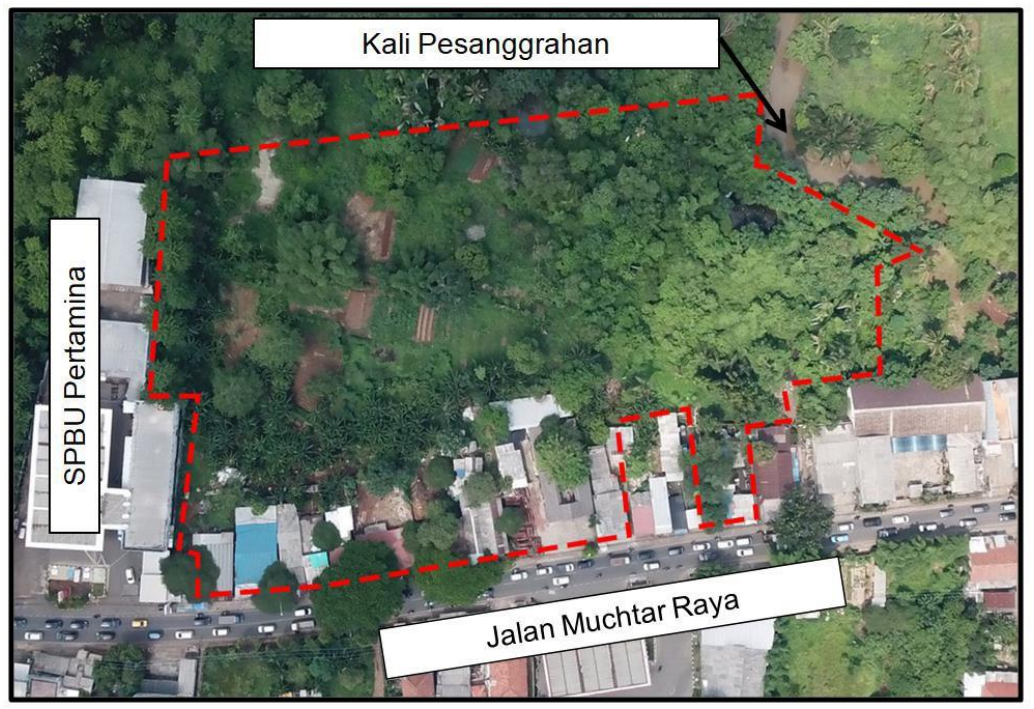

Gambar 1. Lokasi Objek Penelitian

Sumber: Penulis

\section{Pengumpulan Data}

\section{Data Primer}

Data primer merupakan data yang diperoleh dengan melakukan pengamatan secara langsung terhadap objek studi. Data yang diperoleh dapat berupa data kuantitatif dan kualitatif. Pegumpulan data primer dapat dilakukan dengan beberapa metode, yaitu

1. Survey Lapangan

Survey lapangan dilakukan dengan mengamati secara langsung objek studi. Melalui metode ini, peneliti dapat dengan mudah memahami kondisi eksisting objek studi. Dalam studi ini, survey lapangan dilakukan pada objek studi yang telah dipilih, yaitu lahan kosong komersial di Sawangan. Melalui survey lapangan, data primer berupa data kondisi lingkungan sekitar tapak dapat dikumpulkan

2. Wawancara

Wawancara dilakukan untuk memperdalam data primer yang sudah didapatkan melalui survey lapangan terlebih dahulu. Dalam metode ini, peneliti harus menyiapkan daftar pertanyaan untuk memperoleh data - data yang tidak dapat diberikan tanpa ijin dari narasumber yang bersangkutan. Data yang diharapkan untuk diperoleh melalui wawancara yaitu data yang berkaitan dengan legalitas lahan.

3. Dokumentasi

Dokumentasi dilakukan untuk menunjang dari metode survey lapangan dan wawancara. Data - data yang dikumpulkan dengan menggunakan metode tersebut dapat di dokumentasikan dalam bentuk data visual seperti foto. Hasil Dokumentasi tersebut dapat digunakan untuk menggambarkan kondisi eksisting dari objek studi secara visual.

\section{Data Sekunder}

Data sekunder merupakan data yang dapat diperoleh secara tidak langsung melalui media. Media yang digunakan dapat berupa media cetak dan elektronik (internet), serta data dari institusi yang terkait dengan objek studi.

Dalam studi ini membutuhkan data yang sesuai dengan kebutuhan analisis yang akan dilakukan sehingga perlu diketahui ketersediaan data dan disesuaikan dengan kemampuan pengumpulan data baik data primer maupun data sekunder. Berikut adalah tabel kebutuhan data yang diperlukan dalam studi ini. 
Tabel 1. Kebutuhan Data

\begin{tabular}{llll}
\hline \multicolumn{1}{c}{ No } & \multicolumn{1}{c}{ Data } & Bentuk Data & Alat Analisis \\
\hline \multicolumn{2}{c}{ ANALISIS LOKASI \& TAPAK } & & Deskriptif \& SWOT \\
\hline 1 & Karakteristik Lokasi & Peta & \\
\hline \multicolumn{2}{l}{ Aksesibilitas } & & Deskriptif \& SWOT \\
\hline 2 & Jaringan Jalan & Peta dan Tabel & \\
\cline { 2 - 4 } & Rencana Jaringan Jalan & Peta dan Tabel & \\
\hline Rencana Kota & & Deskriptif \& SWOT \\
\hline 3 & Arah Perkembangan Kota & Peta dan Tabel & \\
& & &
\end{tabular}

\begin{tabular}{|c|c|c|c|}
\hline \multicolumn{4}{|c|}{ Tren Pengembangan Kota } \\
\hline 4 & Persebaran Properti & Peta dan Naratif & Deskriptif \& SWOT \\
\hline \multicolumn{4}{|c|}{ Karakteristik Tapak } \\
\hline \multirow[t]{3}{*}{1} & Letak Tapak & & \multirow[t]{6}{*}{ Deskriptif \& SWOT } \\
\hline & Batas Tapak & $\begin{array}{l}\text { Peta, Tabel dan } \\
\text { Naratif }\end{array}$ & \\
\hline & \multicolumn{2}{|l|}{ Pemilik Tapak } & \\
\hline 2 & Pencapaian Sirkulasi & Peta dan Foto & \\
\hline 3 & Visual & Foto dan Naratif & \\
\hline 4 & Aktivitas Lingkungan & Peta dan Naratif & \\
\hline \multicolumn{4}{|c|}{ Kapasitas Ruang } \\
\hline 5 & $\mathrm{KDB}, \mathrm{KLB}, \mathrm{KB}$ & Tabel dan Naratif & \multirow{2}{*}{ Deskriptif } \\
\hline 6 & Nilai Lahan & Tabel dan Naratif & \\
\hline \multicolumn{4}{|c|}{ Legalitas } \\
\hline 1 & Kesesuaian dengan peruntukan & \multirow{2}{*}{ Naratif } & \multirow{2}{*}{ Deskriptif } \\
\hline 2 & Status Hak Kepemilikan & & \\
\hline \multicolumn{4}{|c|}{ ANALISIS PASAR } \\
\hline \multicolumn{4}{|c|}{ Indikator Makro Ekonomi } \\
\hline 1 & Gross Domestic Product & & \\
\hline
\end{tabular}

\begin{tabular}{|c|c|c|c|}
\hline \multirow[t]{6}{*}{1} & Gross Domestic Product & \multirow{6}{*}{ Tabel dan Naratif } & \multirow{8}{*}{ STP dan Deskriptif } \\
\hline & Kurs & & \\
\hline & Inflasi & & \\
\hline & Suku Bunga & & \\
\hline & PDRB Regional & & \\
\hline & $\begin{array}{l}\text { Kependudukan berdasarkan } \\
\text { Mata Pencahariaan }\end{array}$ & & \\
\hline 2 & $\begin{array}{l}\text { Tren Kondisi Perkembangan } \\
\text { Pasar Sekitar (supply and } \\
\text { demand) }\end{array}$ & \multirow{2}{*}{ Peta dan Tabel } & \\
\hline & $\begin{array}{l}\text { Shopping Mall, Hotel, Kantor, } \\
\text { Perumahan, Apartemen }\end{array}$ & & \\
\hline \multicolumn{4}{|c|}{ Demand Supply } \\
\hline 1 & Harga Sewa/Jual Kompetitor & \multirow{3}{*}{ Tabel dan Naratif } & \multirow{3}{*}{$\begin{array}{l}\text { STP, Regresi dan } \\
\text { Deskriptif }\end{array}$} \\
\hline 2 & $\begin{array}{l}\text { Harga Service Charge } \\
\text { Kompetitor }\end{array}$ & & \\
\hline 3 & Demand \& Supply Absorption & & \\
\hline \multicolumn{4}{|c|}{ ANALISIS KEBUTUHAN RUANG } \\
\hline 1 & $\begin{array}{l}\text { Standar Kebutuhan Ruang } \\
\text { Properti Komersial }\end{array}$ & \multirow{4}{*}{ Tabel dan Naratif } & \multirow{4}{*}{ Deskriptif } \\
\hline 2 & KDB KLB & & \\
\hline 3 & Peruntukan Lahan & & \\
\hline 4 & Ketinggian Maksimum & & \\
\hline
\end{tabular}




\begin{tabular}{|c|c|c|c|}
\hline No & Data & Bentuk Data & Alat Analisis \\
\hline 5 & Data Pasar Properti Sekitar & & \\
\hline \multicolumn{4}{|c|}{ ANALISIS PENENTUAN PRODUK } \\
\hline 1 & Harga Tanah & \multirow{7}{*}{ Tabel dan Naratif } & \multirow{7}{*}{ DCF } \\
\hline 2 & Harga Konstruksi & & \\
\hline 3 & Biaya Bangunan & & \\
\hline 4 & Harga Sewa & & \\
\hline 5 & Harga Service Charge & & \\
\hline 6 & Occupancy Rate & & \\
\hline 7 & Suku Bunga & & \\
\hline
\end{tabular}

Sumber: Olahan penulis, 2020

\section{Analisis Data}

Untuk mencapai tujuan penelitian yakni membuat rekomendasi studi High and Best Use pada lahan komersial di Jl Muchtar Raya Sawangan, maka penulis perlu melakukan beberapa analisis dan metode kuantitatif untuk dapat mencapai tujuan tersebut. Analisis dan metode yang digunakan dijabarkan di bawah ini.

a. Analisis Lokasi dan Tapak

Pada analisis ini bertujuan untuk membahas lokasi dan tapak dari Pelabuhan Sunda Kelapa dari segi lokasi dan tapak, sehingga dapat mengetahui potensi dan permasalahan utama dari luar (eksternal) dan dalam (internal) kawasan. Pada pembahasan luar kawasan (eksternal) membahasa mengenai karakteristik lokasi, pencapaian, proximity, rencana kota dan arah pengembangan kota. Sedangkan pada pembahasan dalam kawasan (internal) membahas mengenai karakteristik tapak, pencapaian dan sirkulasi, visual tapak, aktifitas lingkungan, kapastitas ruang dan nilai lahan dan juga legalitas. Setelah dilakukan analisis ini maka dirumuskan dalam potensi dan permasalahan utama dengan menggunakan metode analisis deskriptif dan SWOT.

b. Analisis Pasar

Analisis pasar yang dilakukan adalah analisis pasar mikro, yang akan membahas lebih fokus langsung pada objek studi. Di dalam analisis pasar terdapat analisis kondisi demografi, makro ekonomi, market positioning, competitive Level dan market share, profil lokasi lahan. Analisis pasar akan menggunakan metode STP.

c. Analisis Standar Kebutuhan Ruang

Analisis standar kebutuhan ruang dilakukan guna untuk mengetahui standar dari masingmasing jenis alternatif bangunan yang akan direncanakan untuk dibangun, sehingga mengetahui pembagian dari masing-masing bagian yang dibutuhkan

d. Analisis Investasi / keuangan

Analisis investasi / keuangan dilakukan dengan menggunakan metode kuantitatif dengan alat analisis yakni Discounted Cash Flow untuk mengetahui nilai investasi proyek beserta pengembaliannya. Setelah mendapatkan hasil dari analisis analisis sebelumnya maka akan dihitung apakah pengembangan yang dilakukan dapat menguntungkan bagi pengembangan atau tidak. Analisis investasi merupakan parameter apakah seluruh rangkaian pengembangan yang akan dilakukan dapat dianggap layak secara financial bagi pengembangan pada area lokasi tapak

\section{DISKUSI DAN HASIL}

\section{Analisis Lokasi dan Tapak}

a. Aksesibilitas: Tinjauan aksesibilitas pada lahan objek penelitian ini dilihat dari fungsi jalan dan ketersediaan sarana transportasi umum. Jalan Muchtar Raya merupakan jalan kolektor sekunder yang diapit oleh 2 jalan arteri yaitu Jl Raya Bogor dan JI Raya Sawangan, dengan adanya rencana pelebaran dan rencana pembangunan jalan tol memberikan dampak positif pada lahan tapak. Kemudian dilakukan hasil skoring untuk menemukan penggunaan terbaik 
dilihat dari aksesibilitas dan menghasilkan rank 1 yaitu hunian, ke2 retail dan ke3 Hotel

b. Proximity: Lokasi lahan relative lebih mudah mencapai ke tempat lain dibandingkan dari tempat lain ke lokasi lahan dilihat dari jarak simpul kegiatan menuju lahan yang terdapat perbedaan dari lahan menuju simpul kegiatan. Dilihat dari analisis skoring terhadap pusatpusat kegiatan untuk fungsi yang terbaik dilihat dari kedekatan didapatkan rank 1 adalah hunian, rank 2 retail dan rank 3 hotel.

c. Nilai lahan cenderung memiliki nilai yang masih rendah untuk lahan fungsi komersial, mempunyai range harga $\mathrm{Rp} 2.100 .000-2.300 .000$ untuk nilai pasar terkini

d. Analisis Bencana: lokasi lahan terbebas dari banjir maupun bencana, tingkat bencana di Sawangan sendiri tergolong rendah dilihat dari hasil analisis menggunakan peta RTRW Kota Depok

e. Tren: adanya tren yang mulai mengarah kearah lokasi lahan dilihat dari pembangunanpembangunan infrastruktur yang ada, seperti jalan tol, pembangunan terminal.

f. Analisis Karakteristik Tapak untuk di tapak sendiri mempunyai kontur yang cukup landai yakni di range 1-2 meter.

g. Dimensi Tapak: Luas tapak secara keseluruhan yakni adalah $18.742 \mathrm{~m} 2$ yang belum dilakukan perhitungan peomotongan rumija dan gsb kemudian setelah dilakukan perhitungan mendapatkan luas lahan yang digunakan sebagai wilayah perencanaan bersih adalah 1,7 Ha / $17.170 \mathrm{~m} 2$ yang dimana mempunyai dimensi lahan pada sebelah timur yang menghadap jalan kolektor sekunder atau berbatasan langsung dengan jalan memiliki panjang $140 \mathrm{~m}$. kemudian untuk dimensi selatan tapak mempunyai lebar yaitu $100 \mathrm{~m}$ ke belakang dari batas daerah perenvanaan yang sudah dikurangi oleh rumija total $32 \mathrm{~m}$ dipotong bagian sisi kiri dan kanan masing-masing $12 \mathrm{~m}$.

h. Aktivitas Lingkungan posisi tapak terletak di antara perumahan warga, sehingga perlu dipikirkan hal-hal yang memadai untuk lingkungan di sekitar tapak dalam pemilihan alternatif.

i. Kapasitas Ruang

Tabel 2. Perhitungan Kapasitas Ruang

\begin{tabular}{lll}
\hline & Ketentuan & Kapasitas \\
\hline Luas & $\begin{array}{l}17.170 \mathrm{~m} 2 \text { (Sudah dipotong dengan rumija dan } \\
\text { sebagainya) (Telah dilakukan perhitungan di } \\
\text { analisis dimensi tapak) }\end{array}$ & \\
\hline KDB & $60 \%$ & $10.302 \mathrm{~m} 2$ \\
\hline KLB & 6 & $103.020 \mathrm{~m} 2$ \\
\hline KDH & $20 \%$ & $3.434 \mathrm{~m} 2$ \\
\hline GFA & $10.302 \mathrm{~m} 2$ & \\
\hline Jumlah Lantai & 10 & \\
\hline
\end{tabular}

Sumber: Penulis, 2020

j. Legalitas dari hasil analisis untuk jenis properti apa saja yang diizinkan untuk dibangun dihasilkan sebagai berikut untuk retail diizinkan, apartemen diizinkan terbatas dengan syarat KDB maksimal 40\% dari maksimal luas lahan, hotel diizinkan, mix-used minimal $20000 \mathrm{~m} 2$.

\section{Analisis Pasar}

\section{Analisis Pasar Makro}

Kesimpulan hasil pasar analisis makro yang dimana investasi pembangunan dilaksanakan optimalnya pada kuartal 42020 atau kuartal 1 2021, dengan harapan ekonomi Indonesia dan wabah pandemik imbas virus COVID-19 yang mulai membaik. 
Tabel 3. Tabel Ekonomi Makro Indonesia 2015-2020

\begin{tabular}{|c|c|c|c|c|c|}
\hline Tahun & Triwulan & $\begin{array}{l}\text { Pertumbuhan } \\
\text { Ekonomi (PDB) }\end{array}$ & $\begin{array}{l}\text { Suku } \\
\text { Bunga }\end{array}$ & Kurs & Inflasi \\
\hline \multirow[t]{4}{*}{2015} & Q1 & $4,71 \%$ & $7,50 \%$ & 13067 & $6,38 \%$ \\
\hline & Q2 & $4,67 \%$ & $7,50 \%$ & 13313 & $7,26 \%$ \\
\hline & Q3 & $4,73 \%$ & $7,50 \%$ & 14657 & $6,83 \%$ \\
\hline & Q4 & $5,04 \%$ & $7,50 \%$ & 13855 & $3,35 \%$ \\
\hline \multirow[t]{4}{*}{2016} & Q1 & $4,92 \%$ & $6,75 \%$ & 13276 & $4,45 \%$ \\
\hline & Q2 & $5,18 \%$ & $6,50 \%$ & 13180 & $3,45 \%$ \\
\hline & Q3 & $5,02 \%$ & $5,00 \%$ & 12998 & $3,07 \%$ \\
\hline & Q4 & $5,03 \%$ & $4,75 \%$ & 13436 & $3,02 \%$ \\
\hline \multirow[t]{4}{*}{2017} & Q1 & $5,01 \%$ & $4,75 \%$ & 13321 & $3,61 \%$ \\
\hline & Q2 & $5,01 \%$ & $4,75 \%$ & 13319 & $4,37 \%$ \\
\hline & Q3 & $5,06 \%$ & $4,25 \%$ & 13425 & $3,72 \%$ \\
\hline & Q4 & $5,19 \%$ & $4,25 \%$ & 13480 & $3,61 \%$ \\
\hline \multirow[t]{4}{*}{2018} & Q1 & $5,06 \%$ & $4,25 \%$ & 13687 & $3,40 \%$ \\
\hline & Q2 & $5,27 \%$ & $5,25 \%$ & 14322 & $3,12 \%$ \\
\hline & Q3 & $5,16 \%$ & $5,75 \%$ & 14854 & $2,88 \%$ \\
\hline & Q4 & $5,18 \%$ & $6,00 \%$ & 14536 & $3,13 \%$ \\
\hline \multirow[t]{4}{*}{2019} & Q1 & $5,07 \%$ & $6,00 \%$ & 14269 & $2,48 \%$ \\
\hline & Q2 & $5,05 \%$ & $6,00 \%$ & 14304 & $3,28 \%$ \\
\hline & Q3 & $5,00 \%$ & $5,25 \%$ & 14080 & $3,39 \%$ \\
\hline & Q4 & $5,04 \%$ & $5,00 \%$ & 14070 & $2,27 \%$ \\
\hline \multirow[t]{4}{*}{2020} & Q1 & $5,05 \%$ & $5,00 \%$ & 14122 & $3,22 \%$ \\
\hline & Q2 & $5,07 \%$ & $4,50 \%$ & 14167 & $3,21 \%$ \\
\hline & Q3 & - & - & - & - \\
\hline & Q4 & - & - & - & - \\
\hline
\end{tabular}

Sumber: Bank Indonesia, 2020

Analisis Pasar Mikro

Tabel 4. Kesimpulan Analisis Pasar Mikro

\begin{tabular}{|c|c|c|c|c|c|}
\hline \multirow[t]{2}{*}{ Rank } & \multirow{2}{*}{$\begin{array}{l}\text { Alternatif } \\
\text { Produk }\end{array}$} & \multicolumn{4}{|c|}{ Kesimpulan } \\
\hline & & Area Pasar & $\begin{array}{c}\text { Market } \\
\text { Share }\end{array}$ & Demand & Harga \\
\hline 1 & Retail & $\begin{array}{l}\text { Penduduk sekitar tapak berskala } \\
\text { community }\end{array}$ & $14,30 \%$ & $\begin{array}{c}36.043 \mathrm{~m} 2 \\
(19.824 \mathrm{~m} 2 \\
\mathrm{NLA})\end{array}$ & $\begin{array}{c}321.652 \\
/ \mathrm{m} 2\end{array}$ \\
\hline 2 & Apartement & $\begin{array}{l}\text { Kecamatan Sawangan dan } \\
\text { Kecamatan Bojongsari }\end{array}$ & $17 \%$ & 392 unit & $14,4 \mathrm{jt} / \mathrm{m} 2$ \\
\hline 3 & Hotel & $\begin{array}{l}\text { Pengunjung Taman Wisata pasir } \\
\text { putih, D kandang amazing Farm, } \\
\text { Golf Sawangan dan Business }\end{array}$ & $12,37 \%$ & 79 room & $\begin{array}{l}528.000 \\
\text { /night }\end{array}$ \\
\hline
\end{tabular}

Sumber: Olahan penulis, 2020

Kesimpulan analisis pasar mikro untuk alternatif pertama yaitu hunian apartement potensi pasarnya sendiri masih mengalami kesulitan yang dimana untuk di kawasan Sawangan sendiri masih banyaknya rencana dari hunian landed yang dimana masih bersaing bersaing dengan 
landed house.kemudian alternatif kedua yaitu Hotel yang menghasilkan hasil analisis yaitu konsep pengembangan jika dilakukan berada di kelas bintang 3 , kemudian diihat dari perhitungan demand yang ada memiliki kecenderungan akan terjadi over supply jika dilanjutkan. Yang ketiga yaitu alternatif retail dengan skala community area dengan mengedepankan konsep pengembangan food and beverage dan juga yang dapat bermanfaat untuk masyarakat sekitar di sekitar tapak. Sejauh ini alternatif retail merupakan alternative terbaik jika dilihat pada analisis pasar.

\section{Analisis Standar Kebutuhan Ruang}

Pada analisis aspek standar kebutuhan ruang ini yang perlu ditinjau adalah kebutuhan ruang dari masing-masing alternatif yang dikaitkan dengan standar yang berlaku dan dipakai di Indonesia.

\section{Standar Kebutuhan Ruang Retail}

Analisis standar kebutuhan ruang retail dilakukan untuk mengetahui dasar kebutuhan ruang yang dipakai yang selanjutnya dikaitkan dengan standar ukuran pusat perbelanjaan yang dapat diterapkan di Indonesia. Berikut pada tabel 5 merupakan hasil dari perhitungan analisis standar kebutuhan ruang alternatif retail.

Tabel 5. Standar Kebutuhan Ruang Retail

\begin{tabular}{|c|c|c|c|c|}
\hline \multicolumn{3}{|c|}{1 Land Area } & \multirow{2}{*}{$\begin{array}{l}17.170 \\
10.302\end{array}$} & \multirow{2}{*}{$\begin{array}{l}\mathrm{m} \mathbf{2} \\
\mathrm{m} 2\end{array}$} \\
\hline 1.1 & Koefisien Dasar Bangunan & $60 \%$ & & \\
\hline 1.2 & Koefisien Lantai Bangunan & 2 & 34.340 & $\mathrm{~m} 2$ \\
\hline 1.3 & Koefisien Dasar Hijau & $20 \%$ & 3.434 & $\mathrm{~m} 2$ \\
\hline 1.4 & Koefisien Tapak Basement & $60 \%$ & 10.302 & $\mathrm{~m} 2$ \\
\hline \multicolumn{2}{|c|}{ Lot Parkir available per basement } & 25 & 412,08 & Lot \\
\hline \multirow{2}{*}{\multicolumn{2}{|c|}{ kebutuhan basement }} & & 824 & Lot \\
\hline & & & 1,999611726 & Lantai \\
\hline 1.5 & Infrastruktur (jalan) & $15 \%$ & $2.575,5$ & $\mathrm{~m} 2$ \\
\hline \multicolumn{2}{|c|}{ Luas GFA } & \multicolumn{3}{|c|}{34.340} \\
\hline$A$ & Saleable & $60 \%$ & \multicolumn{2}{|l|}{20.604} \\
\hline B & Non saleable & $40 \%$ & \multicolumn{2}{|l|}{13.736} \\
\hline 2.1 & Saleable & \multicolumn{3}{|c|}{20.604} \\
\hline$A$ & Food court & $10 \%$ & \multicolumn{2}{|l|}{$2.060,4$} \\
\hline B & F \& B Area & $35 \%$ & \multicolumn{2}{|l|}{$7.211,4$} \\
\hline C & Entertainment & $10 \%$ & \multicolumn{2}{|l|}{$2.060,4$} \\
\hline D & Supermarket & $25 \%$ & \multicolumn{2}{|l|}{5.151} \\
\hline$E$ & Specialty Store & $20 \%$ & \multicolumn{2}{|l|}{$4.120,8$} \\
\hline \multicolumn{5}{|c|}{$100 \%$} \\
\hline 2.2 & Non Saleable & \multicolumn{3}{|c|}{13.736} \\
\hline$A$ & Public facilities & $35 \%$ & \multicolumn{2}{|l|}{$4.807,6$} \\
\hline$B$ & Corridor \& ME & $65 \%$ & \multicolumn{2}{|l|}{$8.928,4$} \\
\hline
\end{tabular}

Sumber: Olahan penulis, 2020

\section{Standar Kebutuhan Ruang Apartemen}

Analisis standar kebutuhan ruang apartement dilakukan untuk mengetahui dasar kebutuhan ruang yang dipakai. Hasil perhitungan dari analisis kebutuhan ruang apartemen ini sendiri berdasarkan pada hasil analisis pasar yang sudah dilakukan pada analisis sebelumnya yang dimana untuk tingkat penyerapannya tidak lebih dari 392 unit. Berikut pada tabel merupakan hasil dari perhitungan analisis standar kebutuhan ruang alternatif apartemen. 
Tabel 6. Standar Kebutuhan Ruang Development Area Apartemen

\begin{tabular}{|c|c|c|c|c|c|c|}
\hline \multirow[t]{3}{*}{1} & \multicolumn{3}{|c|}{ Land Area } & \multirow{3}{*}{$\begin{array}{l}17.170 \\
3.500\end{array}$} & & \multirow{3}{*}{$\frac{\mathrm{m} 2}{\mathrm{~m} 2}$} \\
\hline & A & Koefisien Dasar & Maks & & & \\
\hline & & Bangunan & $40 \%$ & & & \\
\hline & B & $\begin{array}{l}\text { Koefisien Lantai } \\
\text { Bangunan }\end{array}$ & 6 & 103.020 & & $\mathrm{~m} 2$ \\
\hline & $\mathrm{C}$ & Koefisien Dasar Hijau & $20 \%$ & 3.434 & & $\mathrm{~m} 2$ \\
\hline & D & $\begin{array}{l}\text { Koefisien Tapak } \\
\text { Basement }\end{array}$ & $40 \%$ & 3.500 & & $\mathrm{~m} 2$ \\
\hline & \multicolumn{2}{|c|}{ Lot Parkir available per basement } & 25 & 140 & & Lot \\
\hline & & Parkir & & 392 & & Lot \\
\hline & \multirow[t]{3}{*}{$E$} & Infrastruktur (jalan) & $40 \%$ & 6.868 & & $\mathrm{~m} 2$ \\
\hline & & Parkir Outdoor & $70 \%$ & $4.807,6$ & 192,304 & lot \\
\hline & & Kebutuhan Basement & & 3.500 & 392 & lot \\
\hline
\end{tabular}

Sumber: olahan penulis, 2020

Tabel 7. Standar Kebutuhan Ruang Unit Apartemen

\begin{tabular}{|c|c|c|c|c|}
\hline \multicolumn{5}{|c|}{ Apartemen } \\
\hline Luas GFA & & 28.000 & & \\
\hline Luas Efektif & $60 \%$ & 16.800 & & \\
\hline Non Efektif & $40 \%$ & 11.200 & & \\
\hline Saleable Area & $70 \%$ & 11.442 & & \\
\hline \multirow[t]{3}{*}{ Non-Saleable Area } & $30 \%$ & 5.358 & & \\
\hline & & 16.800 & & \\
\hline & Tipe Unit & Proporsi & Luas & Unit/Lot \\
\hline \multirow[t]{4}{*}{ Saleable } & & 11.442 & & \\
\hline & 19 & $30 \%$ & 2.242 & 118 \\
\hline & 30 & $20 \%$ & 2.340 & 78 \\
\hline & 35 & $50 \%$ & 6.860 & 196 \\
\hline Total & & & 11.442 & 392 \\
\hline Total Lot Parkir & & & & 392 \\
\hline Non-Saleable & & 5.358 & & \\
\hline Public Facilities & $30 \%$ & $1.607,4$ & & \\
\hline Corridor \& ME & $40 \%$ & $2.143,2$ & & \\
\hline Pool Gym & $30 \%$ & $1.607,4$ & & \\
\hline
\end{tabular}

Sumber: Olahan Penulis, 2020

\section{Standar Kebutuhan Ruang Hotel}

Analisis standar kebutuhan ruang hotel dilakukan untuk mengetahui dasar kebutuhan ruang yang dipakai pada hotel dengan kelas bintang 3 . Hasil perhitungan dari analisis kebutuhan ruang hotel ini sendiri berdasarkan pada hasil analisis pasar yang sudah dilakukan pada analisis sebelumnya yang dimana untuk tingkat penyerapannya tidak lebih dari 79 kamar. Berikut pada tabel 8 merupakan hasil dari perhitungan analisis standar kebutuhan ruang alternatif hotel. 
Tabel 8. Tabel Standar Kebutuhan Ruang Hotel DEVELOPMENT AREA

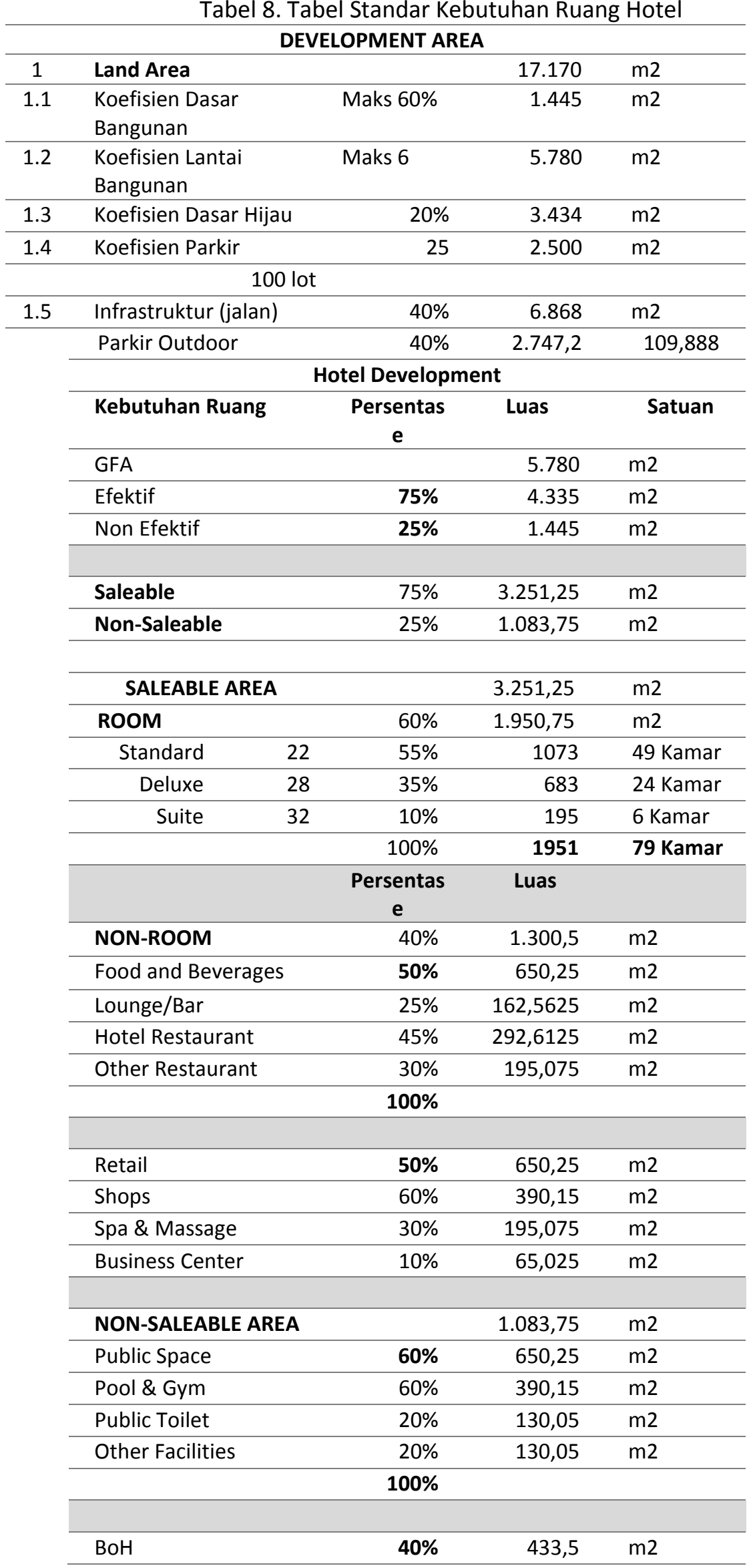

Sumber: Penulis, 2020 


\section{Analisis Finansial}

Pada analisis aspek finansial ini yang perlu ditinjau adalah biaya investasi, pendapatan, pengeluaran dan tentunya arus kas.

a. Cost: Biaya investasi ini sendiri terdiri dari atas tanah, biaya bangunan, biaya perizinan, upah profesional, beban operasional dan biaya fasilitas $\&$ infrastruktur.

Tabel 9. Biaya Investasi dari Masing-masing Alternatif

\begin{tabular}{ccc}
\hline \multicolumn{3}{c}{ BIAYA INVESTASI } \\
\hline RETAIL & HOTEL & APARTEMEN \\
\hline Rp288.103.004.000 & Rp101.095.988.000 & Rp279.438.800.000 \\
\hline Rp8.389.721/ m2 & Rp17.490.655/m2 & Rp9.979.957/ m2
\end{tabular}

Sumber: Olahan penulis, 2020

b. Income: Perencanaan pendapatan untuk tiap alternatif dilihat dari pendapatan sewa / pendapatan jual dan service charge. Pendapatan untuk masing-masing alternatif dapat dilihat pada tabel 10 dibawah ini.

Tabel 10. Tabel Income dari Masing-masing Alternatif Total Income 15 tahun pengembangan

\begin{tabular}{ccc}
\hline RETAIL & HOTEL & APARTEMEN \\
\hline 1.099 .245 .887 .794 & 237.540 .555 .308 & 180.004 .465 .269
\end{tabular}

Sumber: Penulis, 2020

Arus Kas

Analisis arus kas dilihat dari pemasukan dan pengeluaran tiap tahun yang akan dijumlahkan sehingga didapatkan net income atau pendapatan bersih di setiap tahunnya. Setelah didapatkan hasil dari arus kas dilakukan perhitungan terhadap setiap indikatornya. Mencari nilai NPV nya disini menggunakan cara NOI dikalikan dengan discount factor untuk mengubah nilai yang akan datang menjadi nilai sekarang. Apabila NPV lebih besar dari 0 maka investasi dikatakan layak. Sebaliknya jika NPV kurang dari 0 maka investasi dapat dikatakan tidak layak. Hasil analisis finansial dapat dilihat pada tabel 11 dibawah.

Tabel 10. Tabel Hasil Analisis Arus Kas dari Masing-masing Alternatif

\begin{tabular}{|c|c|c|c|c|c|}
\hline \multicolumn{2}{|r|}{ RETAIL } & \multicolumn{2}{|r|}{ HOTEL } & \multicolumn{2}{|c|}{ APARTEMENT } \\
\hline Indikator & & Indikator & & Indikator & \\
\hline IRR & $15,20 \%$ & IRR & $0 \%$ & IRR & $-2 \%$ \\
\hline NPV & Rp41.485.881.445 & NPV & -Rp51.361.392.557 & NPV & - Rp155.352.286.692 \\
\hline PP & 8 & PP & - & PP & - \\
\hline ROI & $71 \%$ & ROI & $-11 \%$ & ROI & $-41 \%$ \\
\hline CASH IN & Rp1.099.245.887.794 & CASH IN & Rp210.531.805.999 & CASH IN & 180.004 .465 .269 \\
\hline $\mathrm{CASH}$ & & CASH & & CASH & \\
\hline OUT & Rp643.684.571.522 & OUT & Rp236.205.209.661 & OUT & 307.382 .680 .000 \\
\hline NETT & & NETT & & NETT & \\
\hline $\mathrm{CASH}$ & & CASH & & CASH & \\
\hline FLOW & Rp455.561.316.272 & FLOW & Rp1.335.345.647 & FLOW & -127.378 .214 .731 \\
\hline PI & 1,707739996 & $\mathrm{PI}$ & 0,891308902 & $\mathrm{PI}$ & 0,585603799 \\
\hline
\end{tabular}

Sumber: Penulis, 2020 


\section{Konsep 3D Visual}

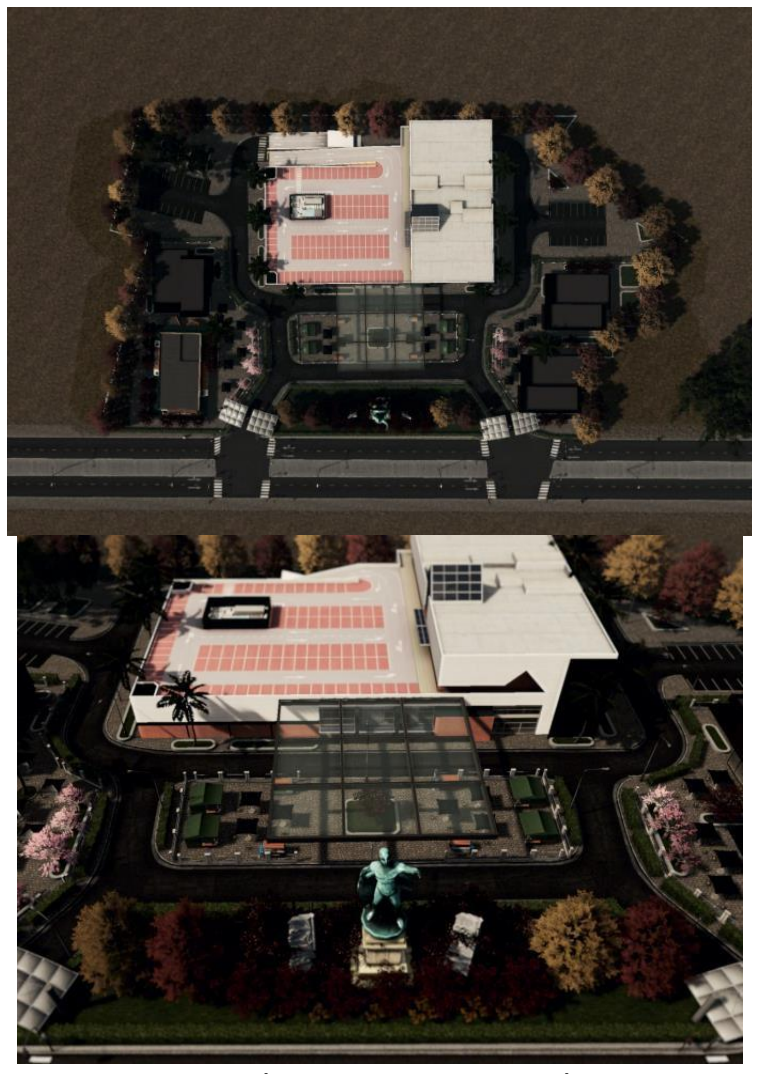

Gambar 2. Konsep Retail

Sumber: Penulis, 2020

\section{KESIMPULAN DAN SARAN Kesimpulan}

Berdasarkan analisis terhadap aspek lokasi, tapak, aspek pasar, aspek kebutuhan ruang dan aspek finansial untuk penggunaan terbaik dan tertinggi pada lahan komersial di Jl Muchtar Raya produk alternatif retail merupakan satu-satunya yang layak diantara kedua alternatif lainnya. Dengan tingkat IRR > Suku Bunga 12\% (15,2\% Retail) yang dimana artinya proyek layak dan dapat dilaksanakan, kemudian NPV $>0$ (Rp41.485.881.445 retail) dan tingkat Profitability Index di angka 1,70 . Konsep pengembangan retail yang akan dikembangkan yakni skala community area dengan mengedepankan konsep pengembangan food and beverage dan juga yang dapat bermanfaat untuk masyarakat sekitar di sekitar tapak

\section{Saran}

1. Berdasarkan hasil dari hasil analisis indikator makro ekonomi, perlu adanya ke hati-hatian dalam menentukan waktu pelaksanaan pembangunan dari proyek pada masa pandemi seperti ini, harus dikaji lebih lanjut mengenai keadaan ekonomi Indonesia yang masih dalam keadaan tidak baik. Yang dimana jika adanya penanganan yang baik atas pandemi COVID-19 ada kemungkinan jika di Q3-Q4 maupun Q1 2021 dapat pulih kembali.

2. Terkait dengan hasil alternatif yakni retail sehingga harus adanya pengkajian lebih lanjut seperti konsep pengembangan retail, seperti pada webinar yang telah dilaksanakan oleh astraland yang dimana cepat atau lambat kebutuhan retail akan dapat kembali seperti semula sebagaimana manusia membutuhkan refreshing / rekreasi, kemudian jika dilihat dari prediksi dari webinar yang dimana nantinya tren dari retail ini sendiri lebih mengarah kepada bagaimana konsep open space yang dimana asumsinya bahwa orang-orang akan merasa lebih aman jika berada di luar ruangan / tidak berada didalam satu ruangan yang berisikan kerumunan orang. 
3. Terkait dengan keterbatasan waktu penulis dalam mengerjakan Tugas Akhir ini, adanya rekomendasi bahwa adanya pengkajian lebih lanjut / analisis pasar lebih lanjut terkait dengan asumsi- asumsi dari perhitungan cashflow agar hasil yang diterima jauh lebih akurat.

\section{REFERENSI}

Barret, V., \& Blair, J. (1988). How to conduct \& analyze real estate market and feasibility studies. New York: Van Nostrand Reinhold.

Kevin dan Utomo C (2017). Analisis Highest and Best Use pada lahan di Jalan Tenggilis Timur 7 Surabaya. Jurnal Teknik, Volume 6(1), D30-D34.

Miles, M., Berens, G., Eppli, M., \& Weiss, M. (2007). Real estate development: principles and process. Washington DC: Urban Land Institute.

Mubayyinah,M., dan Utomo C. (2012). Analisis Highest and Best Use Lahan X untuk Properti Komersial. Jurnal Teknik, Volume 1(1).

The Appraisal Institue (2001). The appraisal of real estate twelfth edition. Chicago:Illinois. 